\begin{tabular}{c}
\hline Review of \\
ECONOMICS \\
and \\
INSTITUTIONS
\end{tabular}

\title{
Do the Rich Vote Conservative Because They Are Rich?
}

\author{
Jo Thori Lind \\ University of Oslo
}

\begin{abstract}
Political economics predicts that the rich oppose redistribution and vote for conservative parties. Although this seemingly fits the data well in most countries, I show that the relationship breaks down when we control for unobservable characteristics. Using Norwegian survey data, I study to what extent voting is caused by income. Although a positive association between income and conservative voting persists when controlling for unobservables, the magnitude of the effect is reduced by a factor of five. To correct for measurement error, I instrument income with average income by profession. The magnitude of the coefficients becomes higher, but the main conclusion remains.
\end{abstract}

JEL classification: C23, C25, D31, D72, H11, H53

Keywords: political economy, redistribution, voting, multinomial logit, panel data

I wish to thank Daron Acemoglu, Erik Biørn, Daniel Chen, John Dagsvik, Bill Kerr, Kalle Moene, Torsten Persson, Knut R. Wangen, and an anonymous referee, as well as participants at meetings of the European Economic Association and the Norwegian Economic Association and seminars at IIES, MIT, the Norwegian School of Economics and Business Administration, the University of Lund, and the University of Oslo for helpful comments and discussions. While carrying out this research I have been associated with the center Equality, Social Organization, and Performance (ESOP) at the Department of Economics at the University of Oslo. ESOP is supported by the Research Council of Norway.

\section{Introduction}

Workhorse models in political economy and public choice subsume that, at least on average, a rich person prefers a lower tax rate than a poor.

Author Address: Department of Economics, University of Oslo, PB 1095 Blindern, 0317 Oslo, Norway. (Email: j.t.lind@econ.uio.no)

\section{Recommended Citation}

Lind J. T. (2010). Do the Rich Vote Conservative because They Are Rich? Review of Economics and Institutions, 1 (2), Article 5. doi: 10.5202/rei.v1i2.5.

Retrieved from http://www.rei.unipg.it/rei/article/view/18 
The reason is simple: The richer you are, the more taxes you pay whereas the benefits remain the same or decline. This is a crucial element of much of political economics, such as the median voter approaches to tax determination (Romer, 1975; Roberts, 1977; Meltzer and Richard, 1981), probabilistic voting approaches (Dixit and Londregan, 1996; Lindbeck and Weibull, 1987), and models of special interest groups (e.g. Grossman and Helpman, 2001). If income does not determine voting, this literature may simply be flawed.

The Meltzer-Richard model, for instance, implies that there is more redistribution the more unequal a society is. Empirically, however, there is no general tendency that unequal societies redistribute more than equal societies. ${ }^{1}$ A proper understanding of the relationship between income, preferences for redistribution, and actual voting is a key to understanding this "redistribution puzzle".

Apparently, the standard political economy prediction of the rich opposing redistribution and voting for conservative parties seems to fit the data well. Figure 1 shows opinions on tax cuts for high incomes and support for the Conservative party by income quintile for a sample of Norwegian respondents. ${ }^{2}$ Respondents in the higher income groups are supportive of tax cuts and they support the Conservative party. Preferences for tax cuts are doubled and conservative voting almost tripled in the 5 th quintile relative to the 1 st and 2 nd.

But this analysis is too simple. First, observable characteristics such as gender and education may have an impact. The conclusions are essentially unchanged if we control for such variables, though. What should be of greater concern are unobservable characteristics that create a spurious correlation between income and conservative voting. There are at least two groups of unobserved differences between agents that we should worry about: Social background and acquired beliefs and norms.

Social background captures a set of value norms and views on the working of society learned at young age. Political sociology suggests that voting is determined by location in social structure and party identification acquired during childhood and adolescence. This means that voting behaviour is heavily affected by the conditions under which a person grew up - persons growing up in a rich and conservative family tends to vote for conservative parties when adults as well. Among the first serious studies of this relationship is Lazarsfeld et al. (1948) seminal study where the emphasis is on the importance of socioeconomic status. ${ }^{3}$

\footnotetext{
${ }^{1}$ See e.g. Bénabou (1996) and Lind (2005) for surveys of these findings.

${ }^{2}$ A description of the data is given in Section 3. Income before 1993 is based on the simulation technique described in Section 2.

${ }^{3}$ Where the level is assigned by interviewers, who are "trained to assess the homes, possessions, appearance, and manner of speech of the respondents and to classify them
} 
Figure 1 - Stated Preferences for Tax Cuts for High Incomes and Fraction Voting Conservative by Income Quintile (cumulative 1977-2001)

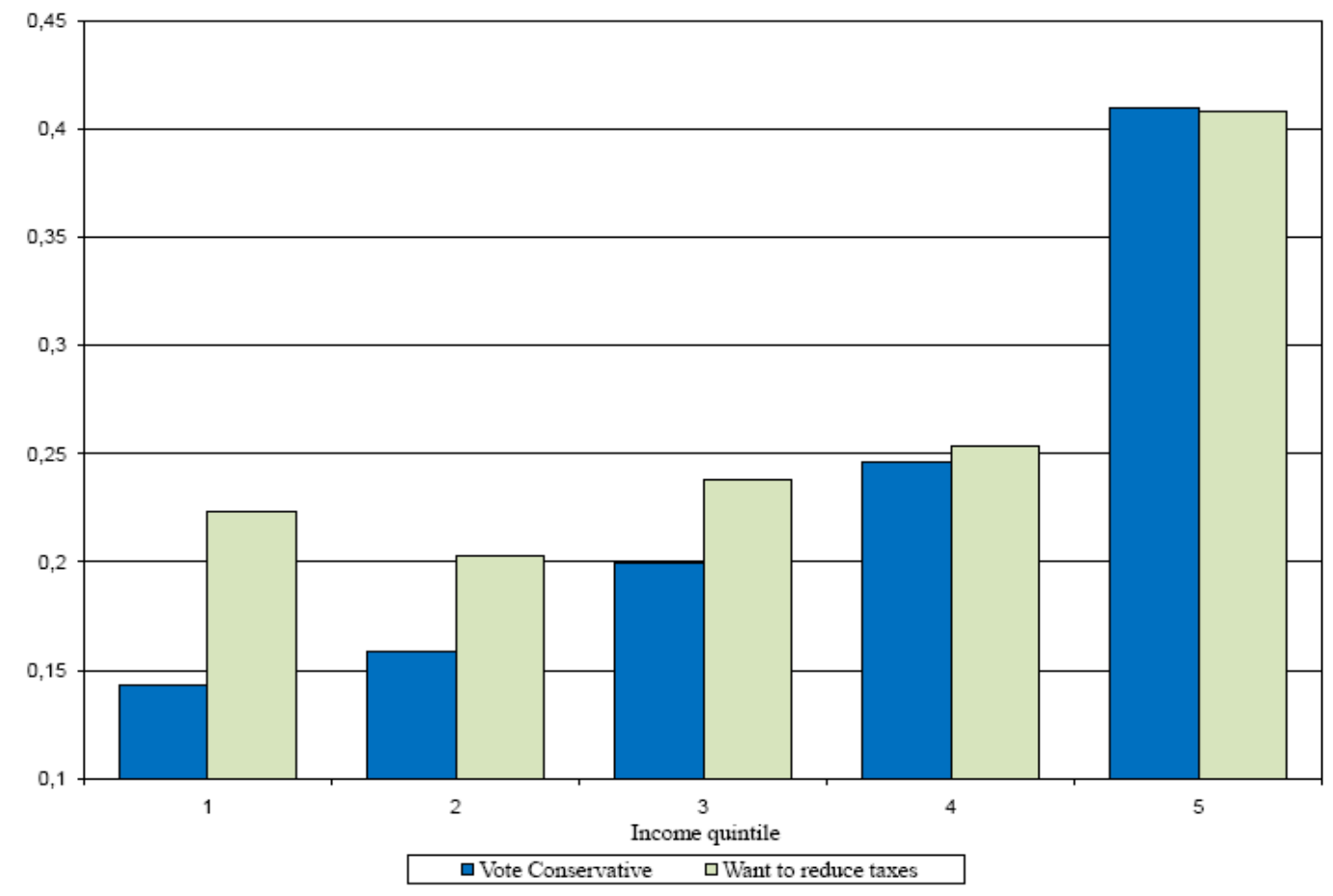

They find a strong relationship between measured socioeconomic status and voting behaviour. Campbell et al. (1960) emphasize instead party identification as a major determinant of voting. They claim that: "[A]n orientation toward political affairs typically begins before the individual attains voting age and [...] this orientation strongly reects his immediate social milieu, in particular his family" (p. 146f). ${ }^{4}$ There is also a voluminous literature on class voting. Very generally, working class background is a good predictor of socialist vote. ${ }^{5}$ A related approach is the model of Corneo and Grüner (2000), where middle class voters oppose redistributing to preserve their social standing relative to the poor. Class background is clearly correlated with income, but this relationship is not causal. In sum, these three channels indicate that there is a correlation between income and conservative voting, but where income has no causal

into their proper stratum in the community according to a set quota. The people with the best homes, furniture, clothes etc., i.e., the ones with most money, would be classed as A's; and the people at the other extreme would be D's" (p. 17).

${ }^{4}$ Niemi and Jennings (1991) confirm the finding that parents play a major role in shaping the offspring's party identification using parent-offspring panel data. See also e.g. Berglund (2004) for a recent study of the Norwegian context.

${ }^{5}$ For instance Nieuwbeerta and Ultee (1999) confirm this on a large number of countries, and the relationship also holds over time, although the strength of class has been declining in most countries. 
effect on voting behaviour. Hence a change in income will not cause to a change in voting behaviour.

The voting decision also depends on beliefs and norms, and these are shaped by own past. Piketty (1995) models social preferences and thus party identification through learning. There is disagreement about the disincentive effects of taxation, and agents learn about the working of the economy through their own experiences as well as that of their ancestors. This generates left-wing dynasties who don't believe in a large degree of social mobility, and hence favour more redistribution than right-wing dynasties, which in general has experienced more upward mobility. The mechanism is also used in Alesina and Angeletos's (2005) model, where preferences for redistribution are shaped by fairness norms, which in turn are shaped by economic behaviour. Both approaches generate positive relationships between income and preferences for low taxes.

To the best of my knowledge, there are no studies that estimate the effect of personal income on voting, controlling for unobserved social background in a satisfactory manner. That is what I do in this paper, and it turns out that controlling for unobservables has a major impact on the estimated effect of income on voting behaviour. The estimation procedure is based on the assumption that during a limited period of time, unobserved characteristics remain constant, so they can be controlled out by an individual specific fixed effect. If a change in income over this period has an impact on expressed political preferences, the income change is the casual effect.

I use panel data from the Norwegian Election Study for the seven elections between 1977 and 2001 where each respondent is interviewed after two consecutive elections. There are several reasons why Norway is a suitable country for this study. First, as it has a proportional electoral system, there are more than two parties and more than one "active" cleavage. Hence there is not the same tendency for convergence toward the middle that is found in most majoritarian polities. Second, there is a clearly right-wing party, the Conservative party, which could potentially attract voters from the whole electorate independently of religious beliefs or ethnic group.

Estimation is based on a random utility framework that leads to a logit type choice structure. ${ }^{6}$ To see the effect of income when unobserved effects are not properly taken into account, I first estimate a random effects model. This model is only consistent if the unobserved component is uncorrelated with income, which I argued above is unlikely. However, this model mimics well the best approaches found in the literature. Under

\footnotetext{
${ }^{6}$ The main reason for using a logit type choice structure is that this is the only parametric specification that allows consistent estimation of discrete choice models with fixed effects.
} 
this specification, there is a strong and significant relationship between income and conservative voting. Next, I concentrate on voters who move from one party to another between two elections. Now the effect of income is much lower, indicating that income plays a smaller role in explaining vote changes. Finally, I introduce a fixed effects logit model to properly control for all unobserved effects. Now the effect of income becomes tiny, about $1 / 5$ of the effect in the initial model, and the coefficient is no longer significant. This shows that the rich vote Conservative, but only to a limited extent because they are rich. Using an instrumental variables approach, I show that the results are not driven by increased attenuation bias when working on differentiated data.

These unobservable characteristics imply that there are two types of comparative statics we can perform: First, we can condition on background and experience and change the agents' income. This is what we associate with a mean preserving spreads, and gives the short run effect of a change in income. Second, we can change both income and background characteristics. Then we would expect to find the same effect as is found in cross sectional analyses ignoring unobservable characteristics of the agents. This is the long run effect of an income change, where the long run may be several generations. These analyses are fundamentally different, and it is crucial to use the right analysis to answer the question one is asking.

There are several strands of literature studying the relationship between economics and voting behaviour. First, there are survey-based studies of the effect of income on preferences for redistribution (Husted, 1989), taxes (Lewis, 1979; Furnham, 1984), and provision of public goods (Bergstrom et al., 1982; Gramlich and Rubinfeld, 1982; Preston and Ridge, 1995). Mueller (1963) uses US survey data on opinions on government programs and possible tax changes. She finds some support for the hypothesis that those who benefit from a program are more positive to it than others. Sanders (1988) mostly confirms her findings, using a different methodology and more recent data. McCarty et al. (2003) find a positive relationship between income and Republican partisanship which has been strengthening over time. They argue that this is due to increased polarization as income inequalities have been increasing. However, they make no real attempts at controlling for unobserved heterogeneity in their study. Their findings have also been contested by Glaeser and Ward (2006) who find a declining magnitude in the positive relationship between country income and the share of Republican votes. In parts of the literature on voting, income is also used as a control variable, but again no attempts for controlling for unobservables is done, and most of the time little emphasis is put on income. It has also been found that persons who believe in upward economic mobility tend to oppose redistributive 
policies and vice versa. In a large international survey, Corneo and Grüner (2002) find strong support for the hypothesis that those who expect to benefit from redistributive programs are more supportive of them than others. Ravallion and Lokshin (2000) find similar results on Russian data, and Alesina and La Ferrara (2002) confirm this result using US survey data.

Another strand of literature investigates how the macroeconomic situations influence the incumbent party's popularity. Douglas Hibbs (2000) has coined the term "bread and peace voting" for such behaviour. On time series data, Kramer (1971) had a seminal contribution. Using cross sectional data, one can distinguish between pocketbook (or egotropic) voting, i.e. how your own economic situation influences support for the incumbent party, and sociotropic voting, how the macroeconomic situation affects voting. There seems to be strong support for sociotropic voting but almost no support for pocketbook voting. ${ }^{7}$ Kinder and Kiewiet $(1979,1981)$ use cross sectional data to distinguish between pocketbook voting, i.e. how your own economic situation influences support for the incumbent party, versus sociotropic voting, how the macroeconomic situation affects voting. On US data, they find strong support for sociotropic voting but almost no support for pocketbook voting. LewisBeck (1986) confirms these findings on data from Britain, France, Germany, and Italy. However, in the symposium on economic voting in Electoral Studies, edited by Lewis-Beck and Paldam (2000), the overall conclusion is somewhat moderated. For most countries there is little support for pocketbook voting, but there are exceptions, most notable Denmark and the UK.

\section{Empirical Model and Estimation}

To estimate a model taking into account some of the features set out above, I equip each voter with a set of preference functions for each party available. We may interpret this as the agent's utility of the given party coming to power. As there is little scope for strategic voting in parliamentary elections, it is natural that the agent also votes for the party he prefers to see in power. Generally, I will talk about the utility he expects to get from voting for a party, rather than from seeing the party in power, and leave the precise interpretation to the reader.

Utility for a party depends on agent and time specific effects, his income, other back-ground variables, and a stochastic component. Assuming a linear structure, agent $i$ gets utility

\footnotetext{
${ }^{7}$ See e.g. Grafstein (2009) for an attempt at explaining this puzzle.
} 


$$
v_{i j t}=\alpha_{i j t}+\beta_{j} y_{i t}+\gamma_{j} z_{i t}+\epsilon_{i j t}
$$

from voting party $j$ at time $t$. In the present work, I only study the effects of the current income $y_{i t} . \alpha_{i j t}$ is a latent party, period, and individual specific term, $z_{i t}$ individual characteristics other than income, and $\epsilon_{i j t}$ a standard extreme value distributed taste shifter. The extreme value distribution gives rise to logit-type choice probabilities, which simplifies the implementation of the maximum likelihood estimation. ${ }^{8}$

Throughout the analysis, I use the specification $\alpha_{i j t}=\alpha_{i j}^{I}+\alpha_{j t}^{T}+$ $\alpha_{j}^{P}$ where $\alpha_{i j}^{I}$ is the individual specific term, which I give different specifications outlined below, $\alpha_{j t}^{T}$ a time-party specific fixed effect, and $\alpha_{j}^{P}$ a parameter which applies if the agent is in his second period of interviewing. Since the model contains the period specific effects $\alpha_{j t}^{T}$, all effects related to incumbency, macroeconomic conditions, popularity of specific politicians, and so forth are controlled for. Standard political economics predict that $\beta_{j}$ is high for right-wing parties and low for socialist or left-wing parties, which is the appropriate alternative hypothesis to test against the null hypothesis $\beta_{j}=0$ for all $j$.

As a benchmark model, consider first a standard random effects model with normally distributed individual effects. The individual effects are here modelled as $\left(\alpha_{i 1}^{I}, \ldots, \alpha_{i N}^{I}\right)^{\prime} \sim N I D\left(0, \sum_{\alpha}\right)$, i.e. independent of income $y_{i}$. Computationally, the model is estimated by Monte Carlo integration: First we draw a sequence of as from the appropriate distribution, then we calculate the implied choice probability for each draw, and finally average over all draws to find the likelihood of the data given the parameters. ${ }^{9}$

For consistency, this model requires the random effects $\alpha_{i j}^{I}$ to be independent of $y_{i j t}$ and $z_{i j t}$. This is a strong and, as argued in the introduction, probably unrealistic assumption. Still, the model is included as it is the most efficient version of the models used in the previous literature.

To solve the problem of unobserved effects correlated with income, we want the $\alpha_{i j}^{I}$ 's be time independent individual specific taste parameter. However, as the sample size increases keeping the number of periods each individual is observed fixed, the number of $\alpha_{i j}^{I}$ 's to estimate increases proportionally. This is Neyman and Scott's (1948) incidental parameter problem. Andersen (1970), however, shows that if we can find a sufficient statistic for the incidental parameters, we may use conditional maximum

\footnotetext{
${ }^{8}$ Notice, however, that since we have individual effects (either random or fixed), we do not have the problem with independence of irrelevant alternatives, and a large family of random utility models can be approximated (McFadden and Train, 2000).

${ }^{9}$ Full details can be found in Appendix B.1.
} 
likelihood, i.e. we maximize the likelihood of the data conditional on a sufficient statistic for the incidental parameters. See also Cox (1975). Chamberlain (1980) has derived a conditional maximum likelihood estimator for fixed effects logit models and shown that knowledge of what parties an agent votes at some time is a sufficient statistic for the individual specific effects. We then use the order in which he votes these parties to estimate the parameters. I limit the exposition to the case of two periods as this is the case we encounter below. Also, for simplicity of notation, I omit the period specific and second period effects. Assume that individual $i$ votes for party $p_{1}$ and $p_{2}$ in period 1 and 2 . Conditional on having voted for parties $p_{1}$ and $p_{2}$, i.e. on one of the two voting sequences $\left(p_{1}, p_{2}\right)$ or $\left(p_{2}, p_{1}\right)$, the probability of this observation is

$$
\frac{\operatorname{Pr}\left(p_{1}, p_{2}\right)}{\operatorname{Pr}\left(p_{1}, p_{2}\right)+\operatorname{Pr}\left(p_{2}, p_{1}\right)}
$$

In Whit the assumption of extreme value distributed residuals, the choice probabilities $\operatorname{Pr}\left(p_{1}, p_{2}\right)$ and $\operatorname{Pr}\left(p_{2}, p_{1}\right)$ have logistic structures where the individual effects enter multiplicatively. Hence they cancel out in this expression. Details of this derivation are given in Appendix B.2.

This estimator is extremely robust to correlation between the unobserved individual effect and the explanatory variables. However, it is also a costly estimator as we only use those observations where the individual has changed the party he voted for and also loose information as we only consider within-variation in regressors and ignore betweenvariation. $^{10}$

A final complication is that for the first periods in the sample, we do not have the precise value of the income $y_{i t}$, only an interval in which it lies. We could then use a dummy variable for each income group, but as these groups change over time, this would not be possible with a panel. Rather, I have used simulated maximum likelihood: I assume that a log normal distribution is a reasonable approximation to the income distribution in each period. Using the number of respondents in each income interval, we can then estimate the two parameters $\mu$ and $\sigma$, the mean and standard deviation of log income, for each period. The estimated parameters for the relevant years are found in Table 1 . One could estimate the parameters of the income distribution jointly with the policy preference parameters, but

\footnotetext{
${ }^{10}$ I have run most of the estimations shown below using another less costly, but also less robust estimator proposed by Chamberlain (1980). This estimator does not have individual fixed effects, but instead random effects that are allowed to be correlated with the average income over the two periods. It turns out that the results are similar to those obtained from the random effects estimator, so I have not included these results in the paper.
} 
for computationally simplicity I use the two step procedure of first estimating the income distribution and then estimating the preference parameters by simulated maximum likelihood. Details on the procedure for simulating incomes are given in Appendix B.4.

\section{The Norwegian Polity and the Data Set}

The model is estimated on data from the Norwegian Election Study, made available through the Norwegian Social Science Data Services. The years 1977 to 2001, a total of seven elections, are used. ${ }^{11}$ The study is a rotating panel where most of the respondents participate in the survey in two consecutive elections. Each survey contains a large number of questions on the respondent's opinion about political question as well as some background variables. Although the questions vary over time, there are some key questions that are asked each time. For our purposes, the most interesting are the party the respondent voted for and a statement of household income. Responses to opinions on economic policy was asked in a different way in 2001, so analyses of political opinions are restricted to a sample from 1977 to 1997. Income is measured by recall, and is a measure of last year's income. With minor modifications, it has been measured by the question "What gross income did you (and your spouse/co-habitee) have [last year]? With gross income, we mean total income before any deductions or tax."

From 1977 to 1989 the respondents were only asked to identify their income group and not the precise income. As explained in Section 2, this is solved by using simulated maximum likelihood. Descriptive statistics on the simulated incomes as well as the stated incomes from 1993 to 2001 are found in Table 1. As expected, real incomes are increasing over the period.

In the present work, I have included some results where I use CPI adjusted income, but I have relied mostly on incomes relative to annual averages, as this is what determine whether an agent gains or looses from a redistributive scheme with a linear tax. Also, I have only looked at the effects of income, ignoring the effect of wealth. The reason is that my data set does not have respondent's wealth. Also, reliable data on wealth are hard to obtain for Norway. Estate taxation, which is an important part of taxation of wealth is in Norway determined at the local level, whereas I study (national) parliamentary elections. Finally, the two are usually

${ }^{11}$ An overview of the whole data set is found in Kiberg et al. (2000). See Statistics Norway (1978) for documentation of the 1977 wave, Statistics Norway (1982) for the 1981 wave, Statistics Norway (1986) for the 1985 wave, Valen et al. (1990, Appendix B) for the 1989 wave, Aardal et al. (1995) for the 1993 wave, Aardal et al. (1999) for the 1997 wave, and Aardal et al. (2003) for the 2001 election. 
reasonably highly correlated, so results that hold on income are likely to be rather similar for wealth.

Table 1 - Descriptive Statistics for Income

\begin{tabular}{|c|c|c|c|c|c|}
\hline Year & $\begin{array}{c}\text { Number of } \\
\text { observations }\end{array}$ & $\begin{array}{c}1000 \\
1997 \text { kroner }\end{array}$ & $\begin{array}{c}\text { Relative to } \\
\text { average }\end{array}$ & $\boldsymbol{\mu}$ & $\sigma$ \\
\hline 1977 & 473 & $\begin{array}{c}251.62 \\
(145.41)\end{array}$ & $\begin{array}{c}1.07 \\
(0.62)\end{array}$ & $\begin{array}{c}4.13 \\
(0.01)\end{array}$ & $\begin{array}{c}0.52 \\
(0.01)\end{array}$ \\
\hline 1981 & 1125 & $\begin{array}{c}265.38 \\
(159.65)\end{array}$ & $\begin{array}{c}1.08 \\
(0.65)\end{array}$ & $\begin{array}{c}4.52 \\
(0.01)\end{array}$ & $\begin{array}{c}0.55 \\
(0.01)\end{array}$ \\
\hline 1985 & 1342 & $\begin{array}{c}267.18 \\
(156.75)\end{array}$ & $\begin{array}{c}1.09 \\
(0.64)\end{array}$ & $\begin{array}{c}4.89 \\
(0.01)\end{array}$ & $\begin{array}{c}0.51 \\
(0.01)\end{array}$ \\
\hline 1989 & 1270 & $\begin{array}{c}322.42 \\
(214.17)\end{array}$ & $\begin{array}{c}1.10 \\
(0.73)\end{array}$ & $\begin{array}{c}5.26 \\
(0.01)\end{array}$ & $\begin{array}{c}0.61 \\
(0.01)\end{array}$ \\
\hline 1993 & 1137 & $\begin{array}{c}354.35 \\
(196.03)\end{array}$ & $\begin{array}{c}1.00 \\
(0.55)\end{array}$ & $\begin{array}{c}5.44 \\
(0.002)\end{array}$ & $\begin{array}{c}0.77 \\
(0.001)\end{array}$ \\
\hline 1997 & 1114 & $\begin{array}{c}401.51 \\
(221.77)\end{array}$ & $\begin{array}{c}1.00 \\
(0.55)\end{array}$ & $\begin{array}{c}5.62 \\
(0.002)\end{array}$ & $\begin{array}{c}0.78 \\
(0.001)\end{array}$ \\
\hline 2001 & 557 & $\begin{array}{c}451.72 \\
(374.97)\end{array}$ & $\begin{array}{c}1.00 \\
(0.83)\end{array}$ & $\begin{array}{c}5.85 \\
(0.003)\end{array}$ & $\begin{array}{c}0.73 \\
(0.001)\end{array}$ \\
\hline Total & 7018 & $\begin{array}{c}325.93 \\
(218.21)\end{array}$ & $\begin{array}{c}1.05 \\
(0.65)\end{array}$ & & \\
\hline
\end{tabular}

Sample averages of income and income relative to year average by year, with standard deviations in parenthesis. Numbers up to 1989 are based on 100 simulations. Parameters $\mu$ and $\sigma$ are estimated parameters based on a log normal distribution, used to simulate incomes throughout the paper. Results for 1993 to 2001 are only included for reference. Standard errors of the estimates in parenthesis.

Throughout the paper, I group the parties into five groups. Each party group's vote share in the sample and at the elections are given in Table 2. The Socialist parties consist of the Socialist Left party as well as the Norwegian Communist Party and the Workers' Communist Party. The second group is the Labour party. As this is the largest group, I use it as the reference group. Then follows the Centrist parties which consist of the Centre Party, the Liberal party (Venstre), the Liberal Popular Party, and the Christian Popular Party. The Conservative party (Høyre) is grouped alone as is the Progress party. There seems to be a slight under reporting of voting Progress relative to the outcomes of elections, but otherwise the data seem to reflect the actual outcomes fairly well.

The best overview of Norway's political history and political landscape up to the 1960s is still Rokkan (1967). In his path breaking study, he distinguished between five dimensions of conflict in Norwegian politics. These are (1) the territorial (center vs. periphery), (2) the sociocultural, (3) the religious, (4) an economic conflict on the commodity market (producers vs. buyers of agricultural products), and finally (5) an economic conflict on the labour market. For our purposes, the last cleavage, which corresponds to the traditional division between 
(economic) right and left, is the important one. Over the last 30 years, this has also probably been the most important one. Rasch (2003) reviews a number of studies who attempt to order the Norwegian parties from left to right using survey data on electors, interview of politicians and political experts, studies of party programs, and studies of parliamentary voting. Quite generally, these studies support the ordering Socialist-LabourCentrist-Conservative-Progress. The Progress Party, however, is somewhat unclear and is placed between Labour and Centrist by some studies. For this reason, I consider the Conservative party as the advocate for low taxes and study to what extent Conservative voting is associated with high incomes.

Table 2 - Descriptive Statistics for Party Choice

\begin{tabular}{|c|c|c|c|c|c|c|}
\hline Year & Socialist & Labour & Centre & Conservative & Progress & Total \\
\hline \multirow[t]{3}{*}{1977} & 29 & 208 & 110 & 122 & 4 & 473 \\
\hline & 6.1 & 44.0 & 23.3 & 25.8 & 0.9 & 100 \\
\hline & 4.6 & 42.3 & 21.2 & 24.5 & 1.9 & 94.5 \\
\hline \multirow[t]{3}{*}{1981} & 63 & 437 & 233 & 353 & 39 & 1,125 \\
\hline & 5.6 & 38.8 & 20.7 & 31.4 & 3.5 & 100 \\
\hline & 6.0 & 37.1 & 17.0 & 31.8 & 4.5 & 96.4 \\
\hline \multirow[t]{3}{*}{1985} & 90 & 505 & 286 & 419 & 42 & 1,342 \\
\hline & 6.7 & 37.6 & 21.3 & 31.2 & 3.1 & 100 \\
\hline & 6.1 & 40.8 & 18.5 & 30.4 & 3.7 & 99.5 \\
\hline \multirow[t]{3}{*}{1989} & 163 & 446 & 257 & 280 & 124 & 1,270 \\
\hline & 12.8 & 35.1 & 20.2 & 22.1 & 9.8 & 100 \\
\hline & 10.1 & 34.3 & 18.2 & 22.2 & 13.0 & 97.8 \\
\hline \multirow[t]{3}{*}{1993} & 103 & 470 & 322 & 192 & 50 & 1,137 \\
\hline & 9.1 & 41.3 & 28.3 & 16.9 & 4.4 & 100 \\
\hline & 9.0 & 36.9 & 28.2 & 17.0 & 6.3 & 97.4 \\
\hline \multirow[t]{3}{*}{1997} & 95 & 404 & 328 & 181 & 106 & 1,114 \\
\hline & 8.5 & 36.3 & 29.4 & 16.3 & 9.5 & 100 \\
\hline & 7.8 & 35.0 & 26.1 & 14.3 & 15.3 & 98.5 \\
\hline \multirow[t]{3}{*}{2001} & 84 & 132 & 148 & 145 & 48 & 557 \\
\hline & 15.1 & 23.7 & 26.6 & 26.0 & 8.6 & 100 \\
\hline & 13.8 & 24.3 & 21.9 & 21.2 & 14.6 & 95.8 \\
\hline \multirow[t]{2}{*}{ Total } & 627 & 2,602 & 1,684 & 1,692 & 413 & 7,018 \\
\hline & 8.9 & 37.1 & 24.0 & 24.1 & 5.9 & 100 \\
\hline
\end{tabular}

First row is number of observations in sample, second year-specific percentage, and third result of elections.

This is also confirmed by respondents' response to questions regarding their preferences over policy issues. Figure 2 show the fraction of respondents who oppose tax cuts and favour extensions of social security by party preference. As both of these answers relate to an extended scope of government, we should expect left wing voters to be more positive to 
the proposed changes. The figure shows that respondents who vote for left wing parties also oppose tax cuts and favour social security extensions.

\section{Figure 2 - Preferences for Tax Cuts and Extensions of Social Security by Party Preference.}

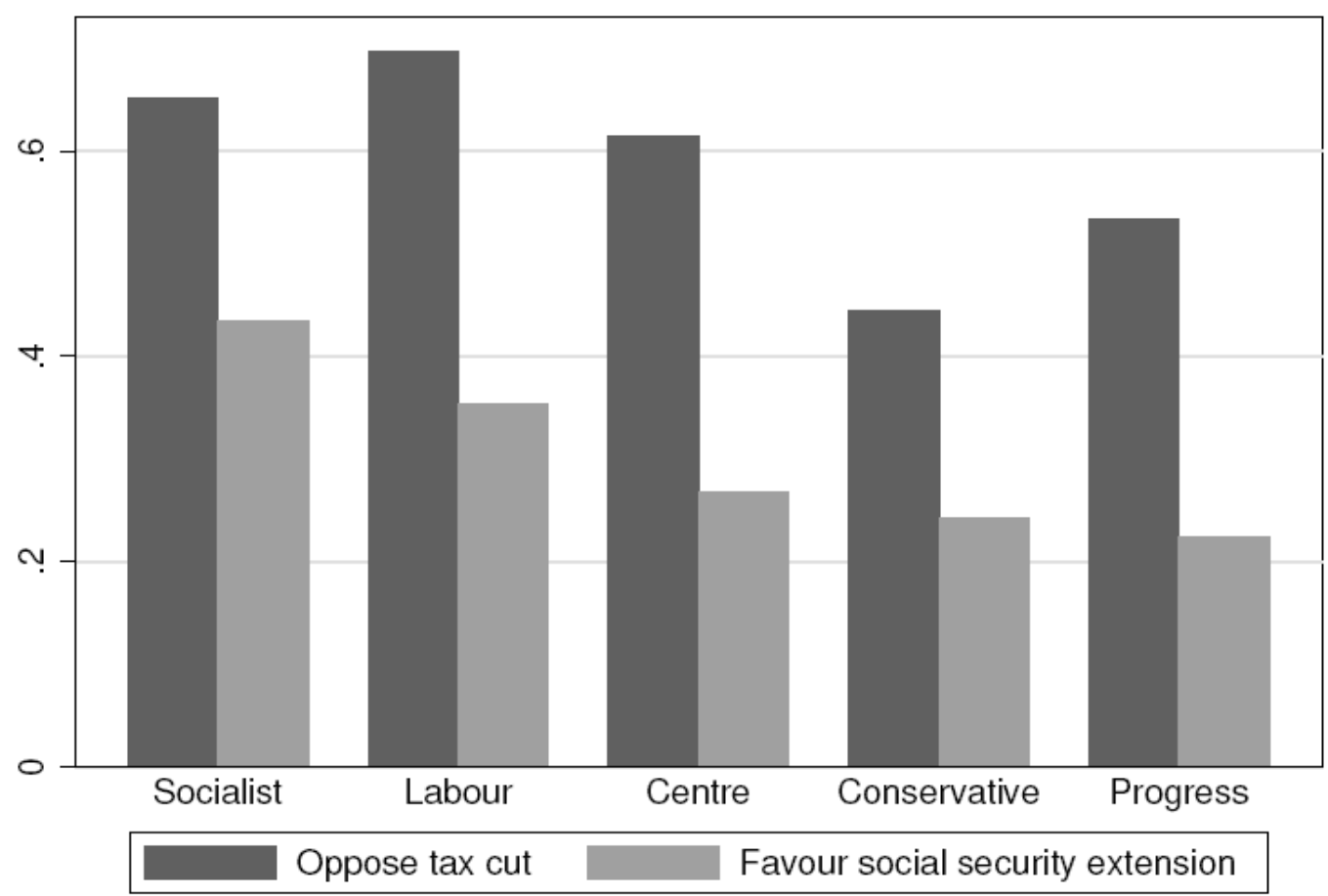

Sample is 1977-97. "Oppose tax cut" are respondents who answer that they oppose or op-pose strongly reductions in the tax rate of high incomes versus those who favour it, favour it strongly, or indifferent. "Favour social security" are respondents who say they favour extensions versus oppose it or indifferent.

\section{Results from the Basic Models}

The results from estimation of the baseline models described above are given in columns (1) to (3) of Table 3. These estimations include income and a vector of control variables consisting of age, two categories of education, and dummy variables for sex, marital status, student, retired, staying at home, employed in the public sector, having zero income, and year. ${ }^{12}$ Sex and age are omitted for the fixed effects model. I have reported results from random effects models on the whole sample and restricting the sample to respondents who vote for different parties in the two waves

\footnotetext{
${ }^{12}$ The reason for not including number of children in the control variables is that this variable first appeared in the survey in 1985. I have ran estimations on the last five periods including number of children; the estimates do not change much (estimates not reported). I have also tried to use income per capita or income adjusted by the OECD equivalence scale. Results are still qualitatively unchanged.
} 
of interviews as well as from the fixed effects models. All the models contain year specific dummies and a dummy for the agent being in his second period of observation. The latter, however, is redundant in the fixed effects model. ${ }^{13}$

Table 3 - Effect of Relative Income on Party Choice

\begin{tabular}{|c|c|c|c|c|}
\hline & $\begin{array}{c}\text { (1) } \\
\text { Random effects }\end{array}$ & $\begin{array}{c}\text { (2) } \\
\text { Random effects }\end{array}$ & $\begin{array}{c}\text { (3) } \\
\text { Fixed effects }\end{array}$ & $\begin{array}{c}\text { (4) } \\
\text { Hausman test }\end{array}$ \\
\hline \multirow[t]{2}{*}{ Socialist } & -0.269 & -0.106 & 0.014 & 0.414 \\
\hline & $(0.202)$ & $(0.175)$ & $(0.357)$ & [0.340] \\
\hline \multirow[t]{2}{*}{ Centre } & -0.615 & -0.077 & -0.114 & 2.421 \\
\hline & $(0.207)$ & $(0.150)$ & $(0.158)$ & [0.008] \\
\hline \multirow[t]{2}{*}{ Conservative } & 1.090 & 0.361 & 0.191 & 2.142 \\
\hline & $(0.184)$ & $(0.145)$ & $(0.251)$ & {$[0.016]$} \\
\hline \multirow[t]{2}{*}{ Progress } & 0.123 & -0.033 & -0.305 & 1.048 \\
\hline & $(0.233)$ & (0.190) & $(0.378)$ & [0.147] \\
\hline \multirow[t]{2}{*}{ Joint test } & & & & 19.94 \\
\hline & & & & [0.00051] \\
\hline Log likelihood & -7560.0 & -2556.1 & -463.2 & \\
\hline Observations & 3509 & 890 & 890 & \\
\hline Time frame & \multicolumn{4}{|c|}{$1977-2001$} \\
\hline Sample & Full & Changers & Changers & \\
\hline
\end{tabular}

Values in columns (1) to (3) are coefficient on income measured relative to period averages with standard errors in parenthesis. Control variables are age, two categories of education, and dummy variables for sex, marital status, student, retired, staying at home, employed in the public sector, having zero income, and year. Sex and age are omitted for the fixed effects model.

Hausman test is for equality of parameters between columns (1) and (3), with joint being the test of all four parameters being jointly equal. $p$-values are in square brackets.

Estimation is by simulated maximum likelihood with 100 simulations per observation.

Income relative to annual averages is the main measure of income throughout the paper. Appendix Table A1 reports estimates using income in absolute terms (CPI adjusted to 2001). To facilitate reading of the results, I only report the estimated parameter on income; the full estimation results as well as the estimated covariance matrices of the random effects estimators are available upon request.

To test the validity of the political economy approach to voting behaviour, the most interesting estimates are the income coefficients on the Conservative party. The coefficient is positive and significantly different from zero in both random effects models. This is similar to the evidence in Figure 1. When we restrict attention to party changers, the

\footnotetext{
${ }^{13}$ When we both have an individual fixed effect and a year dummy, introducing a dummy for the second period would result in perfect multicollinearity. This is similar to the difficulty of observing individual, year, and cohort effects.
} 
estimated parameter is much smaller than for the full sample. Already, we see a tendency for conservative voters being rich, but that party changes only to a limited degree can be explained by income. The results from the fixed effects estimations confirm these results: Here the estimated parameter on the Conservative party is even lower, and it is now insignificant. Hence when we control for unobserved characteristics, income has very little explanatory power on Conservative voting. ${ }^{14}$

Another interesting feature of Table 3 is that the socialist parties, which according to the theories of Section 2 should attract the poorest voters, rather seem to attract voters with a relatively high income. But this effect is much smaller than for the Conservative party in all specifications, and in the fixed effects specification it even has a positive sign. Also, the parameter is not significantly different from zero at any conventional level of confidence in any of the specification. This may, however, be due to the reference party being Labour, which also is located toward the left wing.

The Progress party, which is often judged as a populist right-wing party, is slightly troublesome as the estimated parameters do not have a consistent sign. These estimates are also generally not significantly different from zero. This may be explained by the fact that the party to a large extent gets "protest votes". Throughout the period, it was also seen as unlikely that the party would take part in government. Finally, particularly at the end of the sample period, the party's ideology started to include some more left-wing components such as increased emphasis on the public responsibility for the welfare of senior citizens.

Estimation results from the control variables are not reported. Some general significant trends are that age has some impact on increasing support for the Socialist and Progress parties, students tend to vote Socialist and to not vote for the Centre and Progress parties whereas the effect is the opposite for the retired. High education tends to reduce the likelihood of voting Labour, whereas public sector employment increases the probability of voting Socialist and reduce the probability of voting Conservative and Progress. Finally, women are more likely to vote Socialist and Labour.

To test whether the observed difference are statistically significant, Column (4) of Table 3 reports the results from Hausman tests for differences in parameter estimates. The tests are between the full sample random effects specification reported in Column (1) against the fixed

\footnotetext{
${ }^{14}$ One might worry that as we compare different model specifications, the error term has different variances resulting in different scaling of the parameters. This would not affect the marginal effect on the choice probabilities reported in Appendix Table A2 however. As the qualitative results are the same for Tables 3 and A2, this is not a problem.
} 
effects estimates reported in column (3). ${ }^{15}$ Each of the estimated parameters on income are tested individually, and a joint test of all four being jointly equal is also included. The joint test clearly rejects equality at all reasonable levels of significance. It is seen that this is mainly driven by the differences occurring between the estimates on the parameters for the Conservative and the Centre parties.

Estimation using income in price adjusted levels rather than relative income reported in Appendix Table A1 gives qualitatively very similar consolations. The figures reported in Table 3 should be interpreted as parameters in a linearized utility function for voting a given party. It may also be of interest to look at the effect of income on choice probabilities. If $\beta_{j}$ is the coefficient on party $j$ and $P_{j}$ the probability of voting for the party, then we see that

$$
\frac{\partial P_{j}}{\partial y}=P_{j}\left(\beta_{j}-\bar{\beta}\right)
$$

where $\bar{\beta}=\sum P_{j} \beta_{j}$. Estimated choice probabilities corresponding to the estimates of Table 3 are reported in Appendix Table A2, where the $P_{j} \mathrm{~s}$ used are the sample means. Increasing the income by an amount equal to the mean income is seen to increase the probability of voting Conservative by a substantial amount, about 25\%, in the random effects models on the whole sample. Restricting the sample to party changers and by using the fixed effects specification, however, the effect is reduced to about $7 \%$ and $5 \%$.

To conclude this section, it seems that income has a positive effect on Conservative voting. The effect is reduced strongly by focusing on party changers and even more when introducing individual fixed effects. In the latter case, the estimate is reduced by a factor of about 5 relative to the standard random effects specification. I interpret this as income having a smaller effect on Conservative voting when we control for unobserved effects correlated with income. Consequently, by just observing a positive correlation between income and Conservative voting, we tend to overstate the causal effect of income.

${ }^{15}$ It may seem illicit to compare estimation from different samples. The fixed effects estimate, however, may be treated as using the whole sample where respondents who do not change party simply do not provide any additional information. Consequently, this approach is warranted. 


\section{Model Specification and Measurement Error}

Generally, to test how robust the results found above are, I now undertake a number of robustness checks. First, a common parameter on income was estimated for the whole sample in the baseline specification. One may worry that as party platforms have changed over the years, the effect of income on party preferences have also changed. To see whether there is a problem of parameter instability, I have rerun the estimations allowing the parameters on income to vary over time. The upper panel of Table 4 shows results from estimations where the sample was split between 1985 and 1989. It is seen that there is a slight tendency for the parameter on the Conservative party to decline over time. However, for the estimators using party changers and fixed effects, we cannot reject the LR test of no break at a 5\% level of confidence.

Figure 3 - Year Specific Coefficients on Income in the Three Specifications
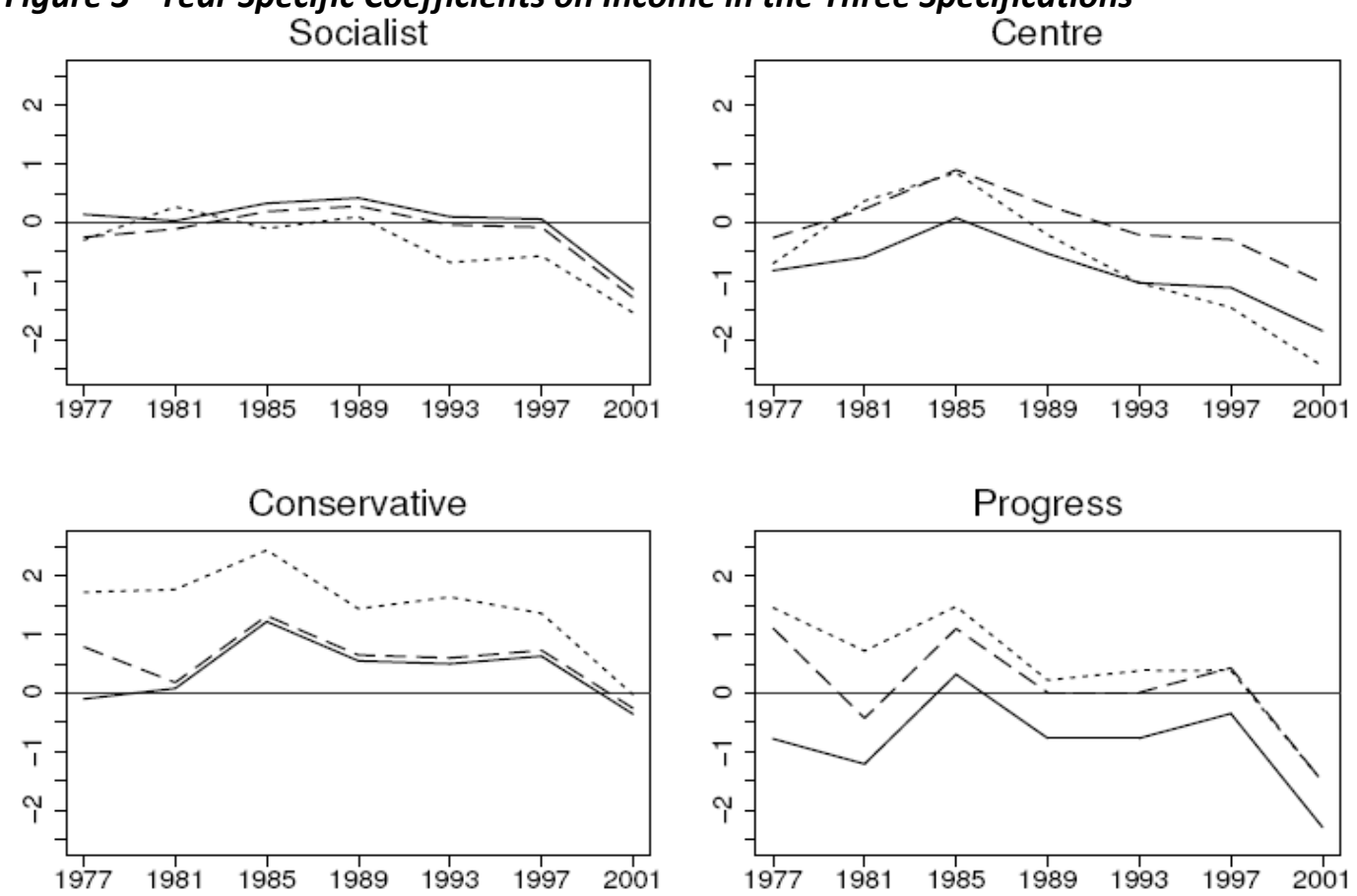

Notes: Fixed effects estimator as solid line, random effects estimator on party changers as dashed line, and random effects estimator on full sample as dotted line.

If we allow for a separate coefficient in each year, we still cannot reject LR tests of no structural change for the fixed effects model, but now both random effects models rejects no structural break at the 5\% level. Figure 3 shows the estimated parameters for each year. We see that almost all parameters have a tendency to fall, indicating increased Labour voting among high income respondents. Focusing on the Conservative party, we 
also see that we have the same ranking of estimates: Full sample random effects indicates a large, albeit falling, effect of income on conservative voting, the changers sample random effects a smaller effect, and the fixed effects the smallest effect.

Table 4 - Stability of the Income Parameters over Time

\begin{tabular}{|c|c|c|c|c|}
\hline & & $\begin{array}{c}(1) \\
\text { Random effects }\end{array}$ & $\begin{array}{c}(2) \\
\text { Random effects }\end{array}$ & $\begin{array}{c}(3) \\
\text { Fixed effects }\end{array}$ \\
\hline \multicolumn{5}{|l|}{ One cut } \\
\hline \multirow[t]{4}{*}{ Socialist } & Income & -0.467 & -0.157 & 0.183 \\
\hline & & $(0.247)$ & (0.193) & $(0.453)$ \\
\hline & Income $x$ & 0.439 & 0.140 & -0.242 \\
\hline & before ' 85 & $(0.363)$ & $(0.343)$ & (0.619) \\
\hline \multirow[t]{4}{*}{ Centre } & Income & -1.250 & -0.323 & -0.220 \\
\hline & & $(0.270)$ & $(0.178)$ & $(0.229)$ \\
\hline & Income $x$ & 1.462 & 0.732 & 0.803 \\
\hline & before ' 85 & $(0.355)$ & $(0.280)$ & $(0.436)$ \\
\hline \multirow[t]{4}{*}{ Conservative } & Income & 0.625 & 0.162 & 0.032 \\
\hline & & $(0.233)$ & $(0.160)$ & (0.319) \\
\hline & Income $x$ & 1.218 & 0.608 & 0.680 \\
\hline & before ' 85 & $(0.329)$ & $(0.270)$ & $(0.463)$ \\
\hline \multirow[t]{4}{*}{ Progress } & Income & -0.358 & -0.210 & -0.520 \\
\hline & & $(0.282)$ & (0.209) & $(0.447)$ \\
\hline & Income $x$ & 1.306 & 0.606 & 0.818 \\
\hline & before ' 85 & $(0.427)$ & $(0.388)$ & $(0.629)$ \\
\hline $\log L$ & & -7549.79 & -2551.67 & -460.59 \\
\hline \multirow[t]{2}{*}{$\chi^{2}(4)$} & & 20.35 & 8.95 & 5.19 \\
\hline & & {$\left[4.27 \times 10^{-4}\right]$} & {$[0.06]$} & {$[0.27]$} \\
\hline \multicolumn{5}{|l|}{ Full specification } \\
\hline Log likelihood & & -7528.57 & -2533.92 & -448.02 \\
\hline \multirow{2}{*}{$\chi^{2}(24)$} & & 62.79 & 44.46 & 30.33 \\
\hline & & {$\left[2.55 \times 10^{-5}\right]$} & {$[0.01]$} & {$[0.17]$} \\
\hline Time frame & & & $1977-2001$ & \\
\hline Sample & & Full & Changers & Changers \\
\hline Observations & & 3509 & 890 & 890 \\
\hline
\end{tabular}

Figures in the first panel are coefficients on income relative to period average and income interacted with a dummy for being observed between 1977 and 1985. Control variables are as in Table 3. $\chi^{2}(4)$ is a LR test for structural break, comparing estimates with Table 3. Standard errors are in parenthesis, $\mathrm{p}$-values in square brackets.

The second panel reports log likelihood for the specification with separate income parameters for each year $\chi^{2}(24)$ is a LR test for the parameters being different, comparing estimates with Table 3. Estimation is by simulated maximum likelihood with 100 simulations per individual.

As estimation is carried out using panel data techniques I only use data on respondents who voted in both periods of interview. We could fear that this leads to a selection bias. To see whether this is that case, I have rerun the estimations including abstention as a separate "party". This has 
very little effect on the other estimates, so I have not included these estimates.

Table 5 - Differences between Increasing and Decreasing Income

\begin{tabular}{|c|c|c|c|c|}
\hline & & $\begin{array}{c}\text { (1) } \\
\text { Random effects }\end{array}$ & $\begin{array}{c}(2) \\
\text { Random effects }\end{array}$ & $\begin{array}{c}\text { (3) } \\
\text { Fixed effects }\end{array}$ \\
\hline \multirow[t]{4}{*}{ Socialist } & Income & -0.170 & -0.183 & -0.485 \\
\hline & & $(0.230)$ & (0.191) & (0.629) \\
\hline & Income $\times$ & -0.180 & 0.172 & 1.027 \\
\hline & Income up & $(0.212)$ & (0.159) & (0.945) \\
\hline \multirow[t]{4}{*}{ Centre } & Income & -0.517 & -0.135 & 0.228 \\
\hline & & $(0.246)$ & (0.164) & (0.509) \\
\hline & Income $x$ & -0.156 & 0.124 & -0.392 \\
\hline & Income up & $(0.261)$ & $(0.137)$ & (0.571) \\
\hline \multirow[t]{4}{*}{ Conservative } & Income & 1.246 & 0.394 & 0.621 \\
\hline & & $(0.240)$ & $(0.156)$ & $(0.550)$ \\
\hline & Income $x$ & -0.240 & -0.072 & -0.613 \\
\hline & Income up & $(0.240)$ & $(0.140)$ & $(0.736)$ \\
\hline \multirow[t]{4}{*}{ Progress } & Income & 0.427 & 0.016 & 0.345 \\
\hline & & $(0.273)$ & $(0.204)$ & $(0.656)$ \\
\hline & Income $x$ & -0.647 & -0.114 & -1.227 \\
\hline & Income up & $(0.281)$ & (0.189) & $(1.040)$ \\
\hline \multirow[t]{2}{*}{$\chi^{2}(4)$} & & 6.39 & 3.52 & 3.42 \\
\hline & & [0.17] & {$[0.48]$} & [0.49] \\
\hline Log likelihood & & -7556.8 & -2554.3 & -461.5 \\
\hline Observations & & 3509 & 890 & 890 \\
\hline Time frame & & & $1977-2001$ & \\
\hline Sample & & Full & Changers & Changers \\
\hline
\end{tabular}

Figures are coefficients on income relative to period average and this variable interacted with a dummy for income increasing between the two periods of observation. Control variables are as in Table 3. $\chi^{2}(4)$ is an LR test on all four interaction terms being zero. Standard errors are in parenthesis, $p$-values in square brackets. Estimation is by simulated maximum likelihood with 100 simulations per individual.

The fixed effects estimator is essentially based on studying whether a change in income tends to push voters toward or away from a party. We may, however, expect an increase and a decrease to have non-symmetrical effects. Table 5 show results from estimations that study this. Here I have interacted income with a dummy variable for increasing income from the first to the second period of interviews. The first thing to notice is that the coefficients on the interaction terms are not jointly significant in any of the specifications, so there is no clear sign of asymmetrical effects of income changes. However, the interaction with increased income seems to have a negative coefficient in many specifications, particularly for the Conservative and the Progress parties. This indicates that an income increase has less of an effect of pulling voters to the Conservative party than a decline has of pushing them away. Overall, there also seems to be a slight tendency for voters to go toward Labour when the income declines. 
This could be motivated by Labour being seen as a safer party than other choices.

For the fixed effects estimator, we only use data on the agents that change party during the two periods. It is possible that those who change their party have preferences that differ from those who stay with the same party in both periods, i.e. we don't have external validity. Obviously, we cannot test this with results from the fixed effects estimator, but results from the random effects estimator give us some insight. Table 6 reports results from an estimation where income has been interacted with a dummy for voting for different parties in the two periods of observation.

Table 6 - Differences between Party Changers and Party Stayers

\begin{tabular}{lcc}
\hline \hline & & Random effects \\
\hline Socialist & Income & -0.856 \\
& & $0.201)$ \\
& & 1.522 \\
Centre & Income $\times$ changer & $0.199)$ \\
& & -0.995 \\
& Income $\times$ changer & $(0.216)$ \\
Conservative & & 1.084 \\
& Income & $(0.234)$ \\
& & 0.856 \\
Progress & Income $\times$ changer & $(0.183)$ \\
& & 0.566 \\
& Income & $(0.202)$ \\
& & -0.829 \\
$\chi^{2}$ (4) & Income $\times$ changer & $(0.277)$ \\
Log likelihood & 2.219 \\
Observations & & $(0.304)$ \\
Time frame & & 61.0 \\
Sample & & {$\left[1.82 \times 10^{-12}\right]$} \\
\hline \hline
\end{tabular}

Figures are coefficients on income relative to period average and this variable interacted with a dummy for voting for different parties in the two periods of observation. Control variables are as in Table 3. $\chi^{2}$ is an LR test on all four interaction terms being zero. Standard errors are in parenthesis, $p$-values in square brackets. Estimation is by simulated maximum likelihood with 100 simulations per individual.

The first thing to notice is that an LR test of all the interaction terms being zero is rejected at a very high level of significance, so there seems to be differences between party changers and party stayers. Furthermore, it seems that income is a better predictor of Conservative voting for party changers than for party stayers. For the other three party groups, the effect seems to be the contrary. To get an idea of who the party changers and 
party stayers are, Tables 7 and 8 report some summary statistics on party choices and demographic characteristics of changers and stayers. Table 7 show that there is higher volatility in voting for parties at the extremes, i.e. Socialist or Progress.

Table 7 - Fraction Changing Party

\begin{tabular}{lcc}
\hline \hline Party & Fraction changing from & Fraction changing to \\
\hline Socialist & 0.41 & 0.42 \\
Labour & 0.18 & 0.17 \\
Centre & 0.23 & 0.26 \\
Conservative & 0.26 & 0.23 \\
Progress & 0.51 & 0.57 \\
\hline Total & 0.25 & 0.25 \\
\hline \hline
\end{tabular}

Fraction of voters who report voting for different parties in the two periods by voting pattern in the first and second period.

Hence party changers have a higher tendency for having voted for one of these party groups in one of the periods of observation.

Table 8 - Characteristics of Party Changers and Party Stayers

\begin{tabular}{lcccc}
\hline \hline & \multicolumn{3}{c}{ Averages } & Logit \\
\cline { 2 - 4 } & Stayers & Changers & Difference & -0.093 \\
Income & 1.05 & 1.06 & 0.004 & $(0.077)$ \\
Change in income & $(0.014)$ & $(0.025)$ & $(0.029)$ & -0.029 \\
& -0.01 & 0.02 & -0.02 & $(0.074)$ \\
Absolute value of & $(0.011)$ & $(0.024)$ & $(0.024)$ & 0.135 \\
change in income & 0.36 & 0.40 & -0.04 & $(0.088)$ \\
Age & $(0.008)$ & $(0.020)$ & $(0.019)$ & -0.022 \\
Female & 48.79 & 43.62 & 5.17 & $(0.003)$ \\
& $(0.291)$ & $(0.477)$ & $(0.571)$ & -0.004 \\
Low education & 0.48 & 0.46 & 0.01 & $(0.079)$ \\
& $(0.010)$ & $(0.016)$ & $(0.019)$ & -0.105 \\
Middle education & 0.42 & 0.37 & 0.06 & $(0.170)$ \\
& $(0.009)$ & $(0.016)$ & $(0.019)$ & -0.064 \\
High education & 0.23 & 0.20 & 0.03 & $(0.185)$ \\
& $(0.008)$ & $(0.013)$ & $(0.016)$ & 0.119 \\
\hline \hline
\end{tabular}

Average values for certain descriptive statistics for voters reporting voting for the same party and different parties in the two periods. Variables are measured in the last period of observation, except changes in income. Forth column is results from a logit model where all variables are combined to explain party change. Standard errors in parenthesis.

Table 8 shows the average of certain demographic characteristics of respondents who voted for the same party and different parties in the two periods as well as results from a logit estimation of the probability of 
changing party. We see that the income level and the change in income between the two periods is almost the same, and does not turn out to be significant in the logit estimation. Large changes in income in absolute value, however, tends to increase the probability of changing party. Age also seem to have an impact on the probability of changing party: Party changers are generally younger whereas older voters seems to have found "their" party to a larger extent. Men and women seems to have approximately the same propensity to change parties, but there is some tendency that higher education increases the probability of changing party. However, the effect of education disappears in the multivariate logit analysis, so this may to a large extent be due to highly educated voters being younger on average than less educated voters.

An important caveat with the results presented above is that income is likely to be measured with error as the data are based on stated recall of last year's income. As usual, this induces an attenuation bias in the results. Furthermore, it is likely that measurement error is more marked in the fixed effects model. The reason is that income is more persistent than the measurement error, so the signal to noise ratio is lower on first differences than on levels. Hence the lower estimate of the effect of income in the fixed effects model than the random effects model may simply be the result of measurement error. As the variance of the measurement error is unknown, we have to attempt some instrumental variables-type estimator.

Assume that we have an instrument that is correlated with the true income, uncorrelated with the measurement error, and that doesn't influence party preferences. For the probit model with normally distributed measurement errors, a number of consistent estimators have been developed (Nelson and Olson, 1978; Newey, 1986). However, as I want to use a fixed effects model, the probit framework is not usable.

I suggest to use a two-stage estimator closely related to the ones suggested by Rivers and Vuong (1988) and Stefanski and Buzas (1995), which in their words is approximately consistent, i.e. it converges in probability to a value approximately equal to the true value. A detailed exposition of the estimator is found in Appendix B.3. The main ingredients are to run a first stage where the explanatory variable measured with error is regressed on the instruments and then estimate the logit model using the predicted values from the first stage. The residuals from the first stage are also included to improve the accuracy of the estimator.

To instrument for income, I use two instruments. The first is the average income of agents of the respondent's profession, measured at the two-digit level using the NYK classification (which is almost identical to the ISIC-58 standard, see Arbeidsdirektoratet, 1995 for details), using the whole sample to calculate the means. The second is year specific averages of the one digit NYK classification to get more variability over time. The 
coding of profession was changed in the 2001 round of the survey, so I only use data from 1977 to 1997 for the IV estimations.

The results are shown in Table 9. The most striking result is that the estimated coefficients are numerically much larger indicating the presence of measurement error in the reported incomes.

Table 9 - Determinants of Opinions on Economic Policy

\begin{tabular}{|c|c|c|c|c|}
\hline & & $\begin{array}{c}\text { (1) } \\
\text { Random effects }\end{array}$ & $\begin{array}{c}\text { (2) } \\
\text { Random effects }\end{array}$ & $\begin{array}{c}\text { (3) } \\
\text { Fixed effects }\end{array}$ \\
\hline \multirow[t]{4}{*}{$A$} & Against tax cuts & -0.700 & -0.066 & -0.071 \\
\hline & Ordinary logit & $(0.080)$ & $(0.097)$ & $(0.125)$ \\
\hline & Log likelihood & -3400.6 & -1201.9 & -592.8 \\
\hline & Observations & 2846 & 896 & 896 \\
\hline \multirow[t]{4}{*}{ B } & For social security extension & -0.261 & -0.023 & -0.045 \\
\hline & Ordinary logit & $(0.088)$ & (0.109) & $(0.151)$ \\
\hline & Log likelihood & -3076.9 & -1029.6 & -496.7 \\
\hline & Observations & 2846 & 853 & 853 \\
\hline \multirow[t]{4}{*}{$\mathrm{C}$} & Against tax cuts & -1.470 & -0.427 & -0.687 \\
\hline & Instrumental variables & $(0.295)$ & $(0.453)$ & $(0.650)$ \\
\hline & Log likelihood & -3078.28 & -1097.28 & -539.096 \\
\hline & Observations & 2642 & 812 & 812 \\
\hline \multirow[t]{6}{*}{$\mathrm{D}$} & For social security extension & -0.382 & -0.220 & -0.301 \\
\hline & Instrumental variables & $(0.325)$ & $(0.479)$ & $(0.712)$ \\
\hline & Log likelihood & -2977.16 & -952.654 & -459.98 \\
\hline & Observations & 2642 & 816 & 816 \\
\hline & Time frame & & 1977-1997 & \\
\hline & Sample & Full & Changers & Changers \\
\hline
\end{tabular}

Estimates are coefficient on income measured relative to period averages. Standard errors in parenthesis. Control variables are as in Table 3, instruments as in Table 9.

Variable "Against tax cut" is one for respondents who answered that they oppose or oppose strongly tax cuts for high incomes and zero for respondents who answer that they favour it, favour it strongly, or don't know. Variable "For social security extension" is one for respondents who answered that they favour or favour strongly extensions of social security, zero for respondents who answered that they oppose it, oppose it strongly, or don't know.

Estimation is by simulated maximum likelihood with 100 simulations per observation

Furthermore, the increase in the parameter values seems to be as large for the random effects models as the fixed effects model, so the lower value in the fixed effects model was not driven by measurement error. Otherwise, the pattern is similar to above: Income has a large and significantly positive effect on preferences for the Conservative party in the random effects model, but the parameter becomes smaller and insignificant once fixed effects are introduced. One objection to these 
results may be that the instrument is invalid as average salary of your profession may be a signal of future income. This would then be an omitted variable in both the baseline estimation and the instrumental variables approach. Call the true coefficient on salary by profession $\pi$ and the bivariate regression coefficient between salary by profession on income $b$. In a linear model, the coefficient on income from an OLS estimation would converge to $(\beta+\pi b) \sigma_{y}^{2} /\left(\sigma_{y}^{2}+\sigma_{u}^{2}\right)$, a combination of the well known results of the effects of omitted variables and errors in variables. If we still include income as the sole explanatory variable, but instrument it with average income by salary, the estimated coefficient converge in probability to $(\beta+\pi b)$. It is probably possible to prove similar results for logit models. This show that even if the instruments should have been included as an explanatory variable, the increase in the estimated parameter values stems from the removal of measurement error. As Table 9 shows that the increase is larger for the random effects models than the fixed effects model, this indicates that the drop in the estimate for the fixed effects model in Table 3 cannot be caused by measurement error in the income variable.

\section{Public Policy Opinions and Party Choice}

So far I have only considered the determinants of voting whereas the literature deals mostly with preferences over taxation and redistribution. The main reason for concentrating on party choice is a revealed preference-argument: It is probably easier to say that you favour redistribution than to actually vote for a party that favours redistribution in a way that may be costly to you. Norway being an egalitarian social democracy, there may also be social norms that makes it harder for some to admit that they want low taxes and don't care about supporting the poor.

Still, it is interesting to see how income and indicators of expectations of income changes affect opinions on economic policy. Table 10 reports results from binomial panel data logit estimations with random and fixed effects. Panel A studies the response to a question on whether the respondent favour a tax cut for those with high incomes. I distinguish between those who answer that they oppose it or oppose it strongly against those who favour it, favour it strongly, or are indifferent. Panel B reports results from a question on whether the respondent believes that social security should be expanded, versus leaving it as it is today or reducing it. Panels $C$ and D study the same outcomes using the instrumental variables technique from Section 5. 
From column (1) of Panel A, we see that in the whole sample, high income is associated with preferences for tax cuts. The coefficient is both numerically relatively large and strongly significantly different from zero. However, we notice that for the sample of agents that changes their opinion on tax cuts, reported in column (2), income has an insignificant, but slightly positive effect on opposing tax cuts. This is also clear when we use the fixed effects estimator reported in column (3). Hence it seems that richer agents favour tax cuts, but an income rise is not a cause of starting to favour tax cuts, so there does not seem to be a causal relationship.

Table 10 - Determinants of Opinions on Economic Policy

\begin{tabular}{|c|c|c|c|}
\hline & $\begin{array}{c}\text { (1) } \\
\text { Random effects }\end{array}$ & $\begin{array}{c}\text { (2) } \\
\text { Random effects }\end{array}$ & $\begin{array}{c}\text { (3) } \\
\text { Fixed effects }\end{array}$ \\
\hline A Against tax cuts & -0.700 & -0.066 & -0.071 \\
\hline Ordinary logit & $(0.080)$ & $(0.097)$ & $(0.125)$ \\
\hline Log likelihood & -3400.6 & -1201.9 & -592.8 \\
\hline Observations & 2846 & 896 & 896 \\
\hline B For social security extension & -0.261 & -0.023 & -0.045 \\
\hline Ordinary logit & $(0.088)$ & (0.109) & $(0.151)$ \\
\hline Log likelihood & -3076.9 & -1029.6 & -496.7 \\
\hline Observations & 2846 & 853 & 853 \\
\hline C Against tax cuts & -1.470 & -0.427 & -0.687 \\
\hline Instrumental variables & $(0.295)$ & $(0.453)$ & $(0.650)$ \\
\hline Log likelihood & -3078.28 & -1097.28 & -539.096 \\
\hline Observations & 2642 & 812 & 812 \\
\hline D For social security extension & -0.382 & -0.220 & -0.301 \\
\hline Instrumental variables & $(0.325)$ & $(0.479)$ & $(0.712)$ \\
\hline Log likelihood & -2977.16 & -952.654 & -459.98 \\
\hline Observations & 2642 & 816 & 816 \\
\hline Time frame & & 1977-1997 & \\
\hline Sample & Full & Changers & Changers \\
\hline
\end{tabular}

Estimates are coefficient on income measured relative to period averages. Standard errors in parenthesis. Control variables are as in Table 3, instruments as in Table 9.

Variable "Against tax cut" is one for respondents who answered that they oppose or oppose strongly tax cuts for high incomes and zero for respondents who answer that they favour it, favour it strongly, or don't know. Variable "For social security extension" is one for respondents who answered that they favour or favour strongly extensions of social security, zero for respondents who answered that they oppose it, oppose it strongly, or don't know.

Estimation is by simulated maximum likelihood with 100 simulations per observation

Panel B confirms to a large extent the conclusions above. For the whole sample, income has the predicted negative effect on preferences for social security extensions. The coefficient is also significantly different from zero. 
For the opinion changing sample, income has an negative effect, but it is now much smaller and insignificant. The same is true when we introduce fixed effects. Hence again, rich agents tend to oppose social security extensions, but probably not because they are rich in itself.

In Panel $C$ we return to the opinions on tax cuts for the rich, now using instrumental variables to correct for measurement error in stated income. As in Table 9, estimated coefficients are numerically considerably larger, indicating the presence of measurement error. For the full sample, income is seen to have a strong negative effect on opposition to tax cuts. Again, if we look at those changing opinions, the effect becomes much smaller, but the reductions seem to be less strong than above. This may indicate that a part of the result stated above was due to more measurement error in the income of those who change their opinion (in the sense of their error having larger variance). Nonetheless, it again turns out that changes in income only has a limited effect on changes in opinion on tax cuts. The conclusions seem to be about the same for Panel D where the instrumental variables estimator is employed on the stated opinion on social security extensions.

\section{Conclusion}

Although there may seem to be a positive relationship between high income and Conservative voting as predicted by most political economy models, this may be due to factors like social background and learning about the working of the economy. In this paper I have used panel data discrete choice models to extract the pure causal effect of income by looking at income changes over a limited period of time and their impact on changes in voting behaviour. The result is that income has a causal effect on Conservative voting, but the effect is smaller in magnitude than what we find using traditional tools. The reduction in magnitude seems to be in the order of a magnitude of five.

The same is true for stated opinions on tax cuts and extension of social security. High income respondents tend to favour tax cuts and oppose social security extensions, but changes in these opinions are only to a limited degree explained by changes in income and does not survive inclusion of individual fixed effects. Opinions in favour of tax cuts and reductions in social security seem to induce Conservative voting as we would expect, but the effect of income on party choice is virtually unchanged from including these opinion variables.

Thus income has most effect on party choice and political preferences in the long run, possibly over several generations. As income levels are quite persistent, this can explain why high income respondents tend to vote 
Conservative and favour a small welfare budget. There could be several explanations for this. One is that permanent income is more relevant for preferences than transitory income (Lind, 2007). As a change in annual income may not have a large impact on lifetime income, we may not expect it to have a large impact on voting. However, it is not obvious that permanent income is more important than current income, given that politics are quite volatile over time. We could also envisage a more sociological impact where a high income tends to socialize people into different groups or classes with different views and beliefs, so people vote in accordance with who they think they are. These perceptions are only changing slowly, which explains why income only has an effect in the long run. It seems that the traditional political economy models, although not proven to be wrong, only tell a part of the story. Unobserved characteristics correlated with income has almost the same impact on voting as income. 


\section{A Additional Estimation Results}

Table A1 - Effect of Income in Constant Prices on Party Choice

\begin{tabular}{lccc}
\hline \hline & $(\mathbf{4})$ & $\mathbf{( 1 )}$ & $\mathbf{( 3 )}$ \\
& Random effects & Random effects & Fixed effects \\
\hline Socialist & -0.273 & -0.131 & -0.107 \\
& $(0.094)$ & $(0.074)$ & $(0.166)$ \\
Centre & -0.577 & -0.159 & -0.065 \\
& $(0.091)$ & $(0.061)$ & $(0.084)$ \\
Conservative & 0.110 & 0.005 & 0.034 \\
& $(0.038)$ & $(0.035)$ & $(0.137)$ \\
Progress & -0.215 & -0.096 & -0.234 \\
& $(0.081)$ & $(0.074)$ & $(0.186)$ \\
\hline Log likelihood & -7575.0 & -2557.8 & -462.5 \\
Observations & 3509 & 890 & 890 \\
Time frame & & $1977-2001$ & \\
Sample & Full & Changers & Changers \\
\hline \hline
\end{tabular}

Values are coefficient on income measured in 100000 1997-NOK. Standard errors in parenthesis. Control variables are as in Table 3. Estimation is by simulated maximum likelihood with 100 simulations per observation.

Table A2 - Marginal Effect of Income on Choice Probabilities

\begin{tabular}{lccc}
\hline \hline & $(\mathbf{1})$ & $\mathbf{( 2 )}$ & $\mathbf{( 3 )}$ \\
& Random effects & Random effects & Fixed effects \\
\hline Socialist & -0.040 & -0.015 & 0.001 \\
& $(0.016)$ & $(0.013)$ & $(0.029)$ \\
Centre & -0.178 & -0.032 & -0.030 \\
& $(0.032)$ & $(0.023)$ & $(0.028)$ \\
Conservative & 0.258 & 0.073 & 0.050 \\
& $(0.032)$ & $(0.022)$ & $(0.041)$ \\
Progress & 0.002 & -0.006 & -0.017 \\
& $(0.011)$ & $(0.009)$ & $(0.019)$ \\
\hline Log likelihood & -7560.0 & -2556.1 & -463.2 \\
Observations & 3509 & 890 & 890 \\
Time frame & & $1977-2001$ & \\
Sample & Full & Changers & Changers \\
\hline \hline
\end{tabular}

Numbers are the estimated marginal effect of income relative to period averages on choice probabilities. Marginal effects are calculated at sample means. Standard errors in parenthesis. Control variables are as in Table 3. Estimation is by simulated maximum likelihood with 100 simulations per observation. 


\section{B Details on the Estimation Procedure}

\section{B.1 Multiple Institutional Indicators}

Preferences over different parties are described by

$$
\begin{aligned}
v_{i j t}= & \alpha_{i j t}+\beta_{j} y_{i t}+\gamma_{j} z_{i t}+\varepsilon_{i j t} \\
& =\alpha_{i j t}+\theta_{j} \mathrm{X}_{i t}+\varepsilon_{i j t}
\end{aligned}
$$

where $X_{i t}=\left(y_{i t} z_{i t}^{\prime}\right)^{\prime}$ and $\theta_{j}=\left(\beta_{j} \gamma\right)$. From this specification, it follows that the probability of agent $i$ choosing party $j$ at date $t$ is

$$
p_{i j t}=\frac{\exp \left(\alpha_{i j t}+\theta_{j} \mathrm{X}_{i t}\right)}{\sum_{k} \exp \left(\alpha_{i k t}+\theta_{k} \mathrm{X}_{i t}\right)}
$$

In the random effects model, the individual effects are assumed to be distributed $\left(\alpha_{i 1}^{I}, \ldots, \alpha_{i \mathrm{~N}}^{I}\right)^{\prime} \sim \operatorname{NID}\left(0, \sum_{\alpha}\right)$ and the probability of choosing party $j$ becomes

$$
p_{i j t}=\int_{\alpha_{\mathrm{i} 1}^{I}} \ldots \int_{\alpha_{\mathrm{iN}}^{I}} \frac{\exp \left(\alpha_{j t}^{T}+\alpha_{j}^{P}+\alpha_{i j}^{I}+\theta_{j} \mathrm{x}_{i t}\right)}{\sum_{k} \exp \left(\alpha_{k t}^{T}+\alpha_{k}^{P}+\alpha_{k j}^{I}+\theta_{k} \mathrm{x}_{i t}\right)} \phi\left(\alpha_{i 1}^{I}, \ldots, \alpha_{i \mathrm{~N}}^{I} ; \sum_{\alpha}\right) d \alpha_{i 1}^{I}, \ldots, d \alpha_{i \mathrm{~N}}^{I}
$$

where $\phi\left(\cdot, \sum_{\alpha}\right)$ is the PDF of a multinomial normal distribution with mean zero and covariance matrix $\sum_{\alpha}$. This expression is computed by Monte Carlo integration, i.e. by simulating the individual specific effects. For each individual, we make $D$ draws $\left\{\tilde{\alpha}_{i 1}^{I \ell} \ldots \tilde{\alpha}_{i N}^{I \ell}\right\}_{\ell=1}^{D}$ from the appropriate normal distribution and replace (A-3) by

$$
\tilde{p}_{i j t}=\frac{1}{D} \sum_{\ell=1}^{D} \frac{\exp \left(\alpha_{j t}^{T}+\alpha_{j}^{P}+\widetilde{\alpha}_{i j}^{I \ell}+\theta_{j} \mathrm{X}_{i t}\right)}{\sum_{k} \exp \left(\alpha_{k t}^{T}+\alpha_{k}^{P}+\widetilde{\alpha}_{k j}^{I \ell}+\theta_{k} \mathrm{X}_{i t}\right)}
$$

As $D$ grows, $\tilde{p}_{i j t}$ converges to the exact value $p_{i j t}$. To enhance the efficiency of the simulation, antithetic variates are used (see e.g. Train, 2003; Section 9.3.1). Adding the likelihoods over individuals and periods, we get the likelihood for the whole sample. Let $v_{i j t}$ be a dummy taking the value 1 if individual $i$ voted party $j$ at time $t$, and 0 otherwise, and let $T_{i}$ be the set of time periods in which individual $i$ is observed. An approximation of the log likelihood for the whole sample is then 


$$
\sum_{i} \ln \frac{1}{D} \sum_{\ell=1}^{D} \prod_{t \in T_{i}} \prod_{j=1}^{N}\left(\frac{\exp \left(\alpha_{j t}^{T}+\alpha_{j}^{P}+\widetilde{\alpha}_{i j}^{I \ell}+\theta_{j} \mathrm{x}_{i t}\right)}{\sum_{k} \exp \left(\alpha_{k t}^{T}+\alpha_{k}^{P}+\widetilde{\alpha}_{k j}^{I \ell}+\theta_{k} \mathrm{x}_{i t}\right)}\right)^{v_{i j t}}
$$

This expression is maximized to obtain estimates of the parameters of interest $\theta_{j}$, as well as the period dummies $\alpha_{j t}^{T}$ and $\alpha_{j}^{P}$ and the values of the Cholesky decomposition of $\sum_{\alpha}$. As in all models of discrete choice, we can only identify the effect of a variable on the choice of an alternative relative to another alternative. Hence we restrict $\theta_{j}=0$ for one party and impose the individual and time effects for the same alternative to be zero, so $\sum_{\alpha}$, the covariance matrix of the individual effects, is in reality of dimension $N-1$.

\section{B.2 The Fixed Effects Estimator}

Fixed effects are handled using Chamberlain's (1980) conditional maximum likelihood estimator. The exposition here is limited to the case of two periods. For simplicity of notation I omit the period specific and second period effects. Then the probability that individual $i$ votes for party $p_{1}$ and $p_{2}$ in period 1 and 2 is

$$
\frac{\exp \left(\alpha_{i p_{1}}^{I}+\theta_{p_{1}} x_{i 1}\right)}{\sum_{k} \exp \left(\alpha_{i k}^{I}+\theta_{k} x_{i 1}\right)} \frac{\exp \left(\alpha_{i p_{2}}^{I}+\theta_{p_{2}} x_{i 2}\right)}{\sum_{k} \exp \left(\alpha_{i k}^{I}+\theta_{k} x_{i 2}\right)}
$$

If $p_{1}=p_{2}$, we can perfectly predict the agent's actions by letting $\alpha_{i p_{1}}^{I}=\alpha_{i p_{2}}^{I} \rightarrow \infty$ and $\alpha_{i k}^{I} \rightarrow-\infty$ for $k \neq p_{1}$. Hence only those who vote for different parties give any information about the parameters of interest $\theta_{j k}$. Conditional on one of the two voting sequences $\left(p_{1}, p_{2}\right)$ or $\left(p_{2}, p_{1}\right)$, the probability of the sequence $\left(p_{1}, p_{2}\right)$ is

$$
\frac{\operatorname{Pr}\left(p_{1}, p_{2}\right)}{\operatorname{Pr}\left(p_{1}, p_{2}\right)+\operatorname{Pr}\left(p_{2}, p_{1}\right)}
$$

For parties $k$ for which $i$ does not vote in any of the two periods, the likelihood is maximized by letting $\alpha_{i k}^{I} \rightarrow-\infty$. We then get the conditional likelihood for individual $i$ as

$$
\frac{\exp \left(\theta_{p_{1}} x_{i 1}+\theta_{p_{2}} x_{i 2}\right)}{\exp \left(\theta_{p_{1}} x_{i 1}+\theta_{p_{2}} x_{i 2}\right)+\exp \left(\theta_{p_{2}} x_{i 1}+\theta_{p_{1}} x_{i 2}\right)}
$$

which is easily maximized to obtain ML estimates of the parameters. 


\section{B.3 The Instrumental Variables Estimator}

Let $y_{i t}^{*}$ denote agent $i$ 's (unobserved) true income and $y_{i t}=y_{i t}^{*}+u_{i t}$ denote the observed income with error. The error $u_{i t}$ is assumed to be iid $\left(0, \sigma_{u}^{2}\right)$ across both $i$ and $t$. The instrument $w_{i t}$ is assumed to satisfy $y_{i t}^{*}=$ $\pi w_{i t}+v_{i t}$ where $\pi \neq 0$ and $v_{i t}$ is iid $\left(0, \sigma_{v}^{2}\right)$. In the first stage we regress $y_{i t}$ on $w_{i t}$. This gives a consistent estimate of $\pi$, so the predicted value $\hat{y}_{i t}$ converges in probability to $y_{i t}^{*}-v_{i t}$ when either the sample size or the number of time periods grows. Also, the residuals $\widehat{u}_{i t}+v_{i t}$ converge in probability to $u_{i t}+v_{i t}$. The utility of voting party $j$ is

$$
v_{i j t}=\alpha_{i j t}+\beta_{j} y_{i t}^{*}+\gamma_{j} z_{i t}+\varepsilon_{i j t}
$$

First, replacing $y_{i t}^{*}$ by $\hat{y}_{i t}$ yields the equation

$$
v_{i j t}^{(1)}=\alpha_{i j t}+\beta_{j} \hat{y}_{i t}+\gamma_{j} z_{i t}+\varepsilon_{i j t} \stackrel{p}{\rightarrow} v_{i j t}+\beta_{j} v_{i t}
$$

Here, $\beta_{j} v_{i t}$, is an unobserved nuisance term. Although it is uncorrelated with $\hat{y}_{i t}$, its variance tends to give a downward bias in the estimates, particularly if the correlation between $y_{i t}^{*}$ and $w_{i t}$ is low. To partially remedy this, I suggest to include $u_{i t}+v_{i t}$ as an additional regressor.

This gives the model

$$
v_{i j t}^{(2)}=\alpha_{i j t}+\beta_{j} \hat{y}_{i t}+\check{\beta}_{j}\left(\widehat{u}_{i t}+v_{i t}\right)+\gamma_{j} z_{i t}+\varepsilon_{i j t} \stackrel{p}{\rightarrow} v_{i j t}-\check{\beta}_{j} u_{i t}+\left(\beta_{j}-\check{\beta}_{j}\right) v_{i t}
$$

Now the nuisance term becomes $-\breve{\beta}_{j} u_{i t}+\left(\beta_{j}-\breve{\beta}_{j}\right) v_{i t}$, which has a lower variance than $\beta_{j} v_{i t}$. To see this, notice that $\breve{\beta}_{j} \stackrel{p}{\rightarrow} \frac{\sigma_{v}^{2}}{\sigma_{u}^{2}+\sigma_{v}^{2}} \beta_{j}$ so the variance of the nuisance term in (A-10) approaches $\frac{\sigma_{u}^{2} \sigma_{v}^{2}}{\sigma_{u}^{2}+\sigma_{v}^{2}} \beta_{j}^{2}$ whereas the variance of the nuisance term in (A-9) approaches $\sigma_{v}^{2} \beta_{j}^{2} \geq \frac{\sigma_{u}^{2} \sigma_{v}^{2}}{\sigma_{u}^{2}+\sigma_{v}^{2}} \beta_{j}^{2}$. Particularly, the nuisance term in (A-10) disappears if either there is no measurement error, i.e. $\sigma_{u}^{2}=0$, or the instrument is perfect, i.e. $\sigma_{v}^{2}=0$. Nevertheless, the unobserved nuisance term leads to a downward bias in this case as well.

Notice that we can estimate $\sigma_{u}^{2}+\sigma_{v}^{2}$ as the variance of $\widehat{u_{i t}+v_{i t}}$ and $\frac{\sigma_{v}^{2}}{\sigma_{u}^{2}+\sigma_{v}^{2}}$ as the ratio $\beta_{j} / \breve{\beta}_{j}$ and hence derive estimates of $\sigma_{u}^{2}$ and $\sigma_{v}^{2}$. This may help us to get an idea of the bias of the estimates. However, knowledge of the variance of the nuisance term in (A-10) is probably not sufficient to get the 
exact bias. Stefanski and Buzas (1995) discuss some possible adjustments based on knowledge of these variances, but their simulations indicate that the improvement in the accuracy of the estimator is not worth the increase in complexity of estimation, so I omit this from the present work.

\section{B.4 The Log Normal Simulation of Income}

We assume that income is log normally distributed, i.e. $\ln y_{i} \sim N\left(\mu, \sigma^{2}\right)$. Then we have

$$
\operatorname{Pr}\left(\underline{y} \leq y_{i} \leq \bar{y}\right)=\Phi\left(\frac{\ln \bar{y}-\mu}{\sigma}\right)-\Phi\left(\frac{\ln \underline{y}-\mu}{\sigma}\right)
$$

where $\Phi$ is the standard normal CDF. We can estimate $\mu$ and $\sigma$ are then estimated from the log likelihood function

$$
\sum_{g=1}^{G} N_{g}\left[\Phi\left(\frac{\ln \bar{y}_{g}-\mu}{\sigma}\right)-\Phi\left(\frac{\ln \underline{y}_{g}-\mu}{\sigma}\right)\right]
$$

where $G$ is the number of income groups, $N_{g}$ is the number of individuals in group $g$ and $\bar{y}_{g}$ and $y_{g}$ the upper and lower incomes in the group. The estimated parameters for the relevant years are found in Table 1 of the main paper. Some respondents have reported zero income. They are left out of the estimation of $\mu$ and $\sigma$, and their income is kept at zero throughout the simulations.

Let $\mathcal{L}\left(y_{i}, z_{i}, \Theta\right)$ denote the appropriate log likelihood function for individual $i$ who has income $y_{i}$, other characteristics $z_{i}$, and where $\Theta$ denotes the parameters to be estimated. We only know that $y_{i}$ is in the interval $(\underline{y}, \bar{y})$. Then the log likelihood given his income group, but ignoring his precise income, is

$$
\frac{1}{\mathrm{~F}(\underline{y})-\mathrm{F}(\bar{y})} \int_{\underline{y}}^{\bar{y}} \mathcal{L}\left(y_{i}, z_{i}, \Theta\right) d \mathrm{~F}(y),
$$

where $\mathrm{F}$ is the $\mathrm{CDF}$ of the income distribution, in this case the log normal. To calculate this integral, I simulate the income of the agent by making a number of draws from the log normal distribution with the appropriate parameters, conditional on the agent being in his income group. 


\section{References}

Aardal, B., Valen, H., \& Berglund, F. (1995). Valgundersøkelsen 1993. Dokumentasjonsrapport. Notater 95/11. Oslo: Statistics Norway (in Norwegian).

Aardal, B., Valen, H., \& Opheim, I. (1999). Valgundersøkelsen 1997. Dokumentasjonsrapport. Rapporter 99/16. Oslo: Statistics Norway (in Norwegian).

Aardal, B., Valen, H., Karlsen, R., Kleven, Ø., \& Normann, T.M. (2003). Valgundersøkelsen 2001. Dokumentasjonsog tabellrapport. Rapporter 2003/14. Oslo: Statistics Norway (in Norwegian).

Alesina, A.F., \& Angeletos, G.M. (2005). Fairness and Redistribution. American Economic Review, 95 (4), 960-80. doi:10.1257/0002828054825655

Alesina, A.F., \& La Ferrara, E. (2002). Preferences for Redistribution in the Land of Opportunities. CEPR Discussion Paper 3155.

Andersen, E. (1970). Asymptotic Properties of Conditional Maximum Likelihood Estimators. Journal of the Royal Statistical Society. Series B (Methodological), 32 (2), 283-301.

Arbeidsdirektoratet (1995). Yrkes-klassifisering. Yrkeliste med NYK-nummer. PB-0544, Oslo: Arbeidsdirektoratet (in Norwegian).

Bénabou, R. (1996). Inequality and Growth. In: Bernanke, B. S., \& Rotemberg, J.J. (Eds.) Macroeconomics Annual, Cambridge, MA: MIT Press.

Berglund, F. (2004). Partiidentifikasjon og Politisk Endring. En Studie av Langsiktige Partitilknytninger Blant Norske Velgere 1965-1997. Oslo: Unipax (in Norwegian).

Bergstrom, T.C., Rubinfeld, D.L., \& Shapiro, P. (1982). Micro-based Estimates of Demand Functions for Local School Expenditures. Econometrica, 50 (2), 1183-1204. doi:10.2307/1911869

Campbell, A., Converse, P.E., Miller, W.E., \& Stokes, D.E. (1960). The American Voter. New York: Wiley.

Chamberlain, G. (1980). Analysis of Covariance with Qualitative Data. Review of Economic Studies, 47 (1), 225-238. doi:10.2307/2297110

Corneo, G., \& Grüner, H.P. (2000). Social Limits to Redistribution. American Economic Review, 90 (5), 1491-1507. doi:10.1257/aer.90.5.1491

Corneo, G., \& Grüner, H.P. (2002). Individual Preferences for Political Redistribution. Journal of Public Economics, 83 (1), 83-107. doi:10.1016/S0047-2727(00)00172-9

Cox, D.R. (1975). Partial Likelihood. Biometrika, 62 (2), 269-276. 
Dixit, A., \& Londregan, J. (1996). The Determinants of Success of Special Interests in Redistributive Politics. Journal of Politics, 58 (4), 1132-1155. doi:10.2307/2960152

Furnham, A. (1984). Determinants of Attitudes Towards Taxation in Britain. Human Relations, 37 (7), 535-546. doi: $10.1177 / 001872678403700703$

Glaeser, E.L., \& Ward, B.A. (2006). Myths and Realities of American Political Geography. Journal of Economic Perspectives, 20 (2), 119-144. doi:10.1257/jep.20.2.119

Grafstein, R. (2009). The Puzzle of Weak Pocketbook Voting. Journal of Theoretical Politics, 21 (4), 451-482. doi:10.1177/0951629809339829

Gramlich, E.M., \& Rubinfeld, D.L. (1982). Micro Estimates of Public Spending Demand Functions and Tests of the Tiebout and Medianvoter Hypotheses. Journal of Political Economy, 90 (3), 536-560. doi:10.1086/261073

Grossman, G.M., \& Helpman, E. (2001). Special Interest Politics. Cambridge, MA: MIT Press.

Hibbs, D.A. (2000). Bread and Peace Voting in U.S. Presidential Elections. Public Choice, 104 (1-2), 149-180.

Husted, T.A. (1989). Nonmonotonic Demand for Income Redistribution Benefits: The Case of AFDC. Sourthern Economic Journal, 55 (3), 710-727. doi:10.2307/1059584

Kiberg, D., Strømsnes, K., Vasstrand, E., \& Klarén, K. (2000). De norske valgundersøkelsene 1977, 1981, 1985, 1989, 1993 og 1997. Dokumentasjon og frekvenser. NSD Rapport 117 (in Norwegian).

Kinder, D.R., \& Kiewiet, D.R. (1979). Economic Discontent and Political Behavior: the Role of Personal Grievances and Collective Economic Judgements in Congressional Voting. American Journal of Political Science, 23 (3), 495-527. doi:10.2307/2111027

Kinder, D.R., \& Kiewiet, D.R. (1981). Sociotropic Politics: the American Case. British Journal of Political Science, 11 (2), 129-161. doi:10.1017/S0007123400002544

Kramer, G.H. (1971). Short-term Fluctuations in U.S. Voting Behavior, 1896-1964. American Political Science Review, 65 (1), 131-143. doi:10.2307/1955049

Lazarsfeld, P.F., Berelson, B., \& Gaudet, H. (1948). The People's Choice. How the Voter Makes up His Mind in a Presidential Campaign. 2nd ed. New York: Columbia University Press.

Lewis, A. (1979). An Empirical Assessment of Tax Mentality. Public Finance, 34 (2), 245-257. 
Lewis-Beck, M.S. (1986). Comparative Economic Voting: Britain, France, Germany, Italy. American Journal of Political Science, 30 (2), 315-346. doi:10.2307/2111099

Lewis-Beck, M.S., \& Paldam, M. (2000). Economic Voting: an Introduction. Electoral Studies, 19 (2-3), 113-121. doi:10.1016/S0261-3794(99)00042-6

Lind, J.T. (2005). Why is There so Little Redistribution? Nordic Journal of Political Economy, 31, 111-125.

Lind, J.T. (2007). Does Permanent Income Determine the Vote? B. E. Journals of Macroeconomics, 7 (1), Article 19. doi:10.2202/1935-1690.1527

Lindbeck, A., \& Weibull J. (1987). Balanced-budget Redistribution as the Outcome of Political Competition. Public Choice, 52 (3), 273-297. doi:10.1007/BF00116710

McCarty, N., Poole, K.T., \& Rosenthal, H. (2003). Political Polarization and Income Inequality. Unpublished paper.

McFadden, D., \& Train, K. (2000). Mixed MNL Models of Discrete Response. Journal of Applied Econometrics, 15 (5), 447-470. doi:10.1002/1099-1255(200009/10)15:5<447::AID-JAE570>3.0.CO;2-1

Meltzer, A., \& Richard, S. (1981). A Rational Theory of the Size of Government. Journal of Political Economy, 89 (5), 914-27. doi:10.1086/261013

Mueller, E. (1963). Political Attitudes Towards Fiscal Programs. Quarterly Journal of Economics, 77 (2), 210-235.

Nelson, F., \& Olson, L. (1978). Specification and Estimation of a Simultaneous-equation Model with Limited Dependent Variables. International Economic Review, 19 (3),: 695-709. doi:10.2307/2526334

Newey, W.K. (1986). Linear Instrumental Variable Estimation of Limited Dependent Variables Models with Endogenous Explanatory Variables. Journal of Econometrics, 32 (1), 127-141. doi:10.1016/0304-4076(86)90015-1

Neyman, J., \& Scott, E.L. (1948). Consistent Estimates Based on Partially Consistent Observations. Econometrica, 16 (1), 1-32. doi:10.2307/1914288

Niemi, R.G., \& Jennings, M.K. (1991). Issues and Inheritance in the Formation of Party Identification. American Journal of Political Science, 35 (4), 970-988. doi:10.2307/2111502

Nieuwbeerta, P., \& Ultee, W. (1999). Class Voting in Western Industrialized Countries, 1945-1990: Systematizing and Testing Explanations. European Journal of Political Research, 35 (1), 123-160. doi:10.1111/1475-6765.00444

Piketty, T. (1995). Social Mobility and Redistributive Politics. Quarterly Journal of Economics, 110 (3), 551-584. doi:10.2307/2946692 
Preston, I., \& Ridge, M. (1995). Demand for Local Public Spending: Evidence from the British Social Attitudes Survey. Economic Journal, 105 (430), 644-660. doi:10.2307/2235023

Rasch, B.E. (2003). Det Politiske Landskap. Stortingsrepresentantenes Oppfatning av Konfliktstrukturen i Partisystemet. Tidsskrift for Samfunnsforskning, 44, 37-66. (in Norwegian).

Ravallion, M., \& Lokshin, M. (2000). Who Wants to Redistribute? The Tunnel Effect in 1990s Russia. Journal of Public Economics, 76 (1), 87-104. doi:10.1016/S0047-2727(99)00064-X

Rivers, D., \& Vuong, Q.H. (1988). Limited Information Estimators and Exogeneity Tests for Simultaneous Probit Models. Journal of Econometrics, 39 (3), 347-366. doi:10.1016/0304-4076(88)90063-2

Roberts, K. W.S. (1977). Voting over Income Tax Schedules. Journal of Public Economics, 8 (3), 329-340. doi:10.1016/0047-2727(77)90005-6

Romer, T. (1975). Individual Welfare, Majority Voting, and the Properties of a Linear Income Tax. Journal of Public Economics, 4 (2), 163-185. doi:10.1016/0047-2727(75)90016-X

Rokkan, S. (1967). Geography, Religion, and Social Class: Crosscutting Cleavages in Norwegian Politics. Ch. 8 in Lipset, S. M., \& Rokkan, S. (Eds.): Party System and Voter Alignments: Cross-National Perspectives, New York: The Free Press.

Sanders, A. (1988). Rationality, Self-interest, and Public Attitudes on Public Spending. Social Science Quarterly, 69 (2), 311-324.

Statistics Norway (1978). Valgundersøkelsen 1977. Dokumentasjon. Mimeo, Statistics Norway (in Norwegian).

Statistics Norway (1982). Storting Elections 1981. Volume II. NOS B297. Oslo: Statistics Norway.

Statistics Norway (1986). Storting Elections 1985. Volume II. NOS B630. Oslo: Statistics Norway.

Stefanski, L.A., \& Buzas, J.S. (1995). Instrumental Variable Estimation in Binary Regression Measurement Error Models. Journal of the American Statistical Association, 90 (430), 541-550. doi:10.2307/2291065

Train, K. (2003). Discrete Choice Methods with Simulation. Cambridge: Cambridge University Press.

Valen, H., Aardal, B., \& Vogt, G. (1990). Endring og Kontinuitet. Stortingsvalget 1989. SØS 74. Oslo: Statistics Norway (in Norwegian). 